\title{
نظرات حول السياسه التشريعيه ونوعية التشريع في الملكك الاردنيه الهاشميه - ا- ( التشريع الدستوري )
}

\author{
shel \\ أ.د / محمد سليم محمدد غزوي \\ استاذ بكليت القانون \\ جامعتّجرارا -الأردن
}




\section{קمن}

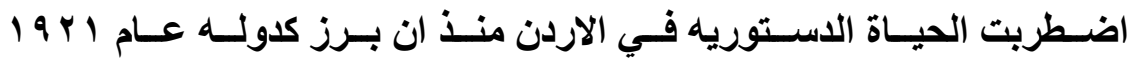

وما بعده وفي عام r 190 " تاريخ صدور الاستور الحالي " تأسس الحكم الاستوري

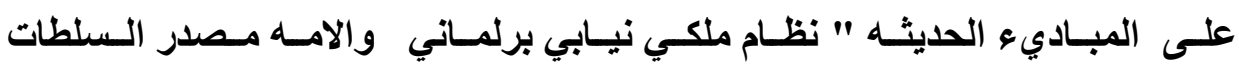

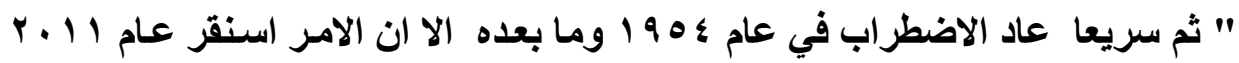

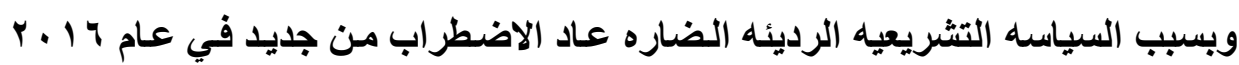

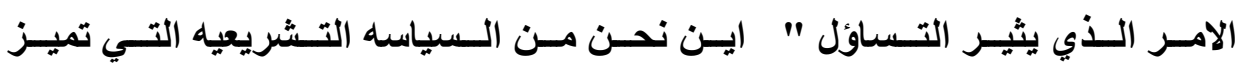

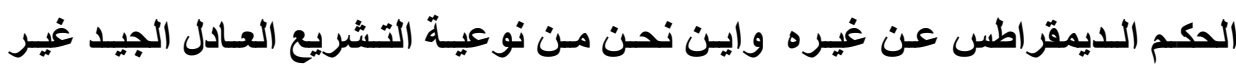

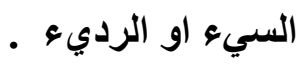




\section{خطبة البحث}

ان القواعد القانونيـه العائده لمختلف فروع القـانون " القانون العـام والقانون principe hierarchie des الخاص " التي يتضمنها مبدأ تسلسل قواعد القانون norms حياة المجتمعات على ان تظل تحت سيطرة احكام الدستور .

ولان القاعـده القانونيـه " علـم وصـنـاعه " علــم يقـوم علـى معرفـة الواقـع وحاجاته و وصتاعه او صياغه يتولاها رجل القانون ليضع الذي يتكون منسه العلم في قالب منضبط صالح للتطبيق العملي

ويطلق لفظ التشريع على كل قاعده قانونيه مكتوبه تصدر من السلطه المختصه بوضع التشريع التي تخضع لمبدأ التسلسل سالف الأكر المؤسس على تدرج السلطات المختصه بموضوعه " التشريع الاستوريه الذي يضعه الشعب او السلطه التاسيسيه والتشريع العادي الأي تضعه السلطه التشريعيه والتشريع الفرعي الأي تسنه السلطه التنفيذيه " وهنا نسأل اين نحن من نوعية التشريع " العلم والصناعه او الصياغه " واين نحن مسن السياسه التشريعيه التـي تميز الحكومسه الديمقراطيـه عـن الحكومسه غير الايمقر (طيه

ولان بحثنا هذا ينصب على " التشريع الاستوري " الذي يحدد شكل الدولهـ ونظام الحكم فيها وسلطاتها الثلاث " التنفيذيه والتشريعيه والقضائيه " وصلتها مـع بعضها او مـع غيرهـا كمـا يحدد حقوق الافراد الاسـاسيه ـ فـاين نحن مـن التشريع 
الاستوري الاردنـي الجيد لا الرديء ؟ واين نحن من استقرار هذا التشريع ونبذ

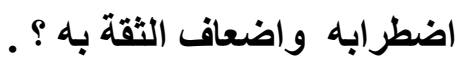

ولان مسن الموضسوعات الهامسه فـي الاردن التـي تـشغل الاوســاط السبياسيه والقانونيه التي تتعلق بالتشريع الدستوري وتثير اسئلة في القانون وتتطلب اجابـة

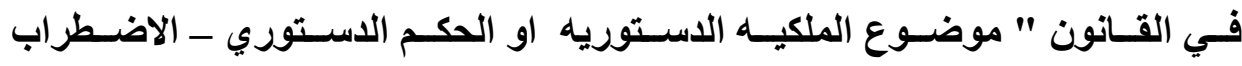

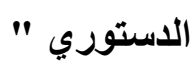
وعليه وحتى يتسنى لنا ايضاح ذلك سنقسم موضوعنا الى فصلين :

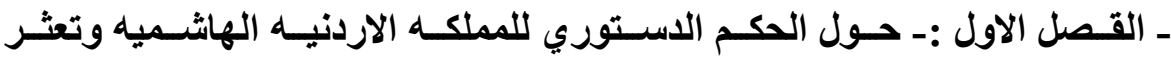

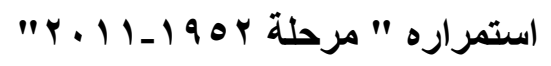

ـ الفصل الثاني :- حول العوده للحكم الاستوري و وبروز العدائيه لاعافة استمراه

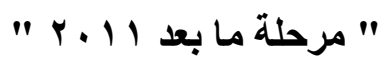




\section{الفصل الاول \\ في هول الهكم الدستوري للامهمبكه الاردنيه الهاشميه

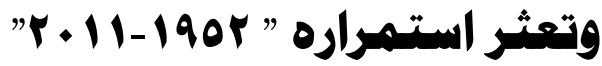

\section{المبمث الاول}

\section{في الالكيه الدستوريه}

لنبأ من البدايه والبدايه ذلك الحدث الهام الذي تم في / / / / 19 1 و وجسد مبدأ

ممارسة السياده السياسيه وهو تـاريخ نشر دستور ب 190 حيث اصبح الاردن دولـه سيده في النطاقين الداخلي والخارجي ـ. وقا ارسى هذا الاستور اسس دولة ديمقراطيه

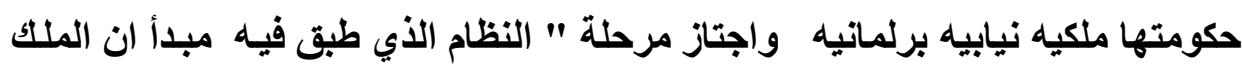
يسود ويحكم regne et gouverne وفقا لنصوص القانون الاساسي الاردني لعام

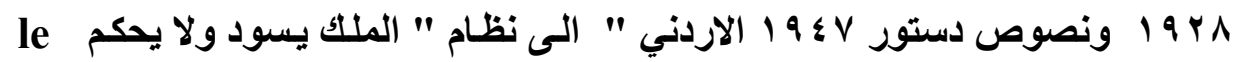
roi regne et ke gouverne pas

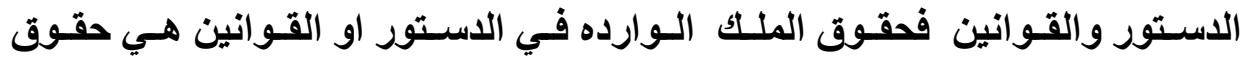
منصوص عليها على سبيل الحصر فان وجد شك على مساله من المسائل ليس للملك ان يطلب ان تكون مـن اختصاصه بـدعوى انـه الاصل في السلطات وانـه صساحب كل سلطه لم يتنازل عنها صراحة لهيئة اخرى . 
وهذا النظام هو النظام الاردني (') يستتتج من الماده ؟r من الاستور " الامـه

$$
\text { مصدر السلطات وتمارس الامه سلطاتها . }
$$

وهنا نسأل فما هي سلطات ملك المملكه الاردنيه الهاشميه وامتيازاته المحدده

$$
\text { على سبيل الحصر ؟ - ع }
$$

مـن المفيد ان نـكر بـان دستور به 9 الاردنسي اعتنق قاعدة " الفصل بين السلطات التي تقوم بـامر الحكم في الاردن وهي : السلطه التشريعيه التي تناطوفقا لنص المـاده هr من الاستور بمجلس الامسه والملك .......... والسلطه التنفيذيـه التي تناطوفقا لنص الماده Y Y من الاستور بالملك ويتولاها بواسطة وزرائه وفق احكام هذا الاستور اما السلطه القضائيه فهي مستقله وفقا لنص الماده VV من الدستور تتولاهـا المحاكم على اختلاف انواعها ودرجاتها وتصدر جميع الاحكام وفق القانون باسم الملك. ونضيف ان نصوص الدستور الاردني جاءت مطبقة لقاعدة " التعاون والتوازن

بين السلطتين التنفيذيه والتشريعيه "

وبالعوده الى الملك وسلطاته () نجدها مبينة ومذكورة في الاستور على سبيل

$$
\text { الحصر وهي تباعا كما يلي : }
$$

1 ـ الملك يفتتح وفقا لنص الماده 9 \من الاستور الدوره العاديه لمجلس الامه بالقاء

خطبة العرش في المجلسين مجتمعين ولـه ان ينيب رئسيس الـوزراء او احـ

(1) بعض الاساتير تنص على ذلك صراحة كالاستور البلجيكي " ليس للملك من السلطات الا ما يخوله

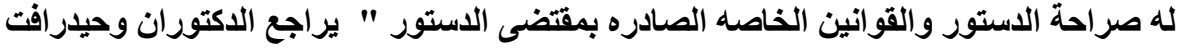

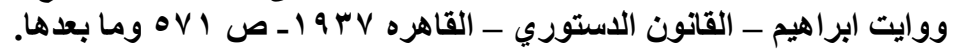

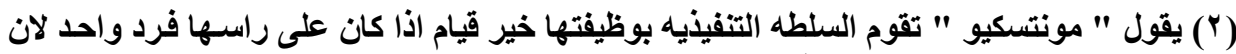

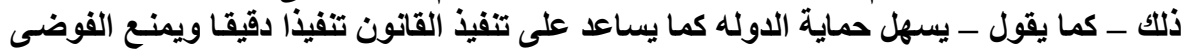

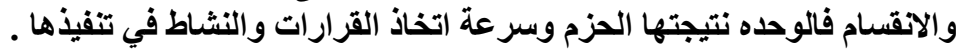


الوزراء ليقوم بمراسم الافتتاح والقاء خطبة العرش ويقدم كل من المجلسين عريضه يضمنه جوابه عنها ـ. وفي هذا فائده حيث ينبه الخطاب الى مسائل هامه وتبحث عند الاجابة عليه السياسه العامه في الدوله . r - والملك راس الدوله وهو مصون وفقا لنص الماده • ب من الدستور من كل تبعة ومسؤوليه عذا المبلأ يعتبر امتياز شخصي وتترتب عليه مجموعه من النتائج وهـي " عدم مسؤلية الملـك جنائيـا وسياسيا ولا يـؤثر المبدأ في مسؤليته

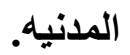

ونضيف ما يترتب ايضا على هذه الصيانه :

أـ " ان اوامر الملك الثفويه او الخطيه وفقا لنص الماده 9 ؛ من الاستور لا تخلي

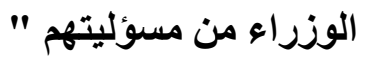

ب- عدم اهلية الملك القيام قي شؤون الدوله بمفرده وهو ما امرت بـه المـاده . ؟1/ من الاستور.

" يمارس الملك صلاحياته بار ادة ملكيه وتكون الاراده الملكيه موقعه من رئيس الـوزراء والـوزير او الـوزراء المختصين يبـي الملك موافقته بتثبيت توقيعهـ فوق التواقيع المذكوره ـ (1)

r- و الملك يصدق على القوانين ويصدرها ويـامر بوضع الانظمـه اللازمـه لتنفيذها بشرط ان لا يتضمن مـا يخـالف احكامسه " ماس من الدستور " وهذا يفيد ان

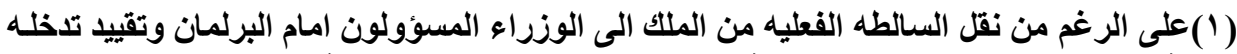

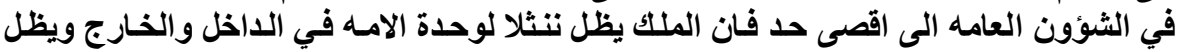

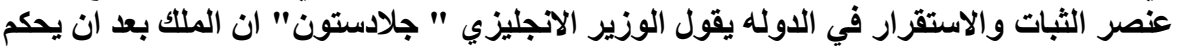

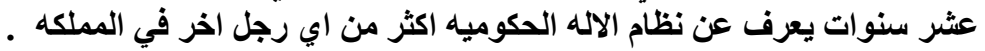


مـصادقة الملـك علـى القـوانين معناهــا انـه لا يمكـن ان يـصدر قـانون يقـره مجلس الامه الا بعد موافقة الملك لهذا تولت المـاده به من الاستور تفصيل

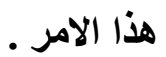

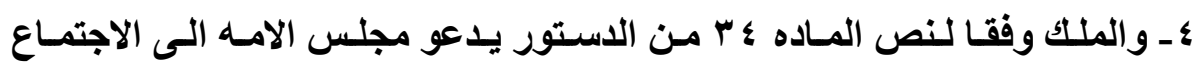
ويفتحه ويؤجله ويفضه وفق احكام الاستور وللملك ان يحل مجلس النواب ، وللملك عندما تحتاج الدوله اثناء العطله البرلمانيه الى البت في امور لا يمكن تقرير هـا الا بواسـطة البرلمـان يـــو مجلس الامسه السى الاجتمـاع في دورات

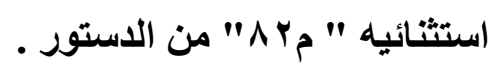

هـ وللملك وفقا لنص المواد Vrی r ترتيب المصالح " ينشيء ويمنح ويسترد الرتب وله حق العفو الخاص ووفقا لنص المـاده r م هو القائـ الاعلى للقوات البريـه والبحريـه والجويـه ووفقا لنص المـاده بr من الدستور يعلن الحرب ويعقد الصلح ويبرم المعاهدات والاتفاقات ، كما يملك سلطه " ملطفه او مخفقه " عندما يعين رئيس الوزراء ويقيله وكذلك الوزراء ويقيلهم . 


\section{المبحث الثاني \\ في الاضطراب الدستوري}

لـم يستمر طويلا هـا النمـوذج " الملكيـه الدسـتوريه " واخـنـا نـشهر حكمـا دستوريا مضطربا جـاء وليد سبب وادى الى نتائج ضساره امـا السبب فيتلخص في

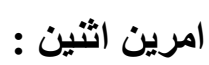

أـ خلـو الاسـتور الاردنـي مـن تنظيم امـر حمايتهـ وبخاصـه مـا يتعلق بالرقابـه

$$
\text { الاستوريه (') الاسئور الأن }
$$

بـ ومـا الامر الثاني فهو مجموع التعديلات التي ادخلت على دستور ب و 190

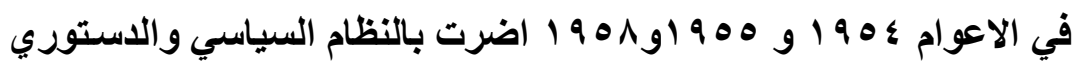
للمملكه وابعدته عن ما امتاز به وهو النظام النيابي البرلماني.

وبهذا يمكنتا القول ان التعديلات سالفة الذكر قد قنت الاضطراب الستوري ولكن كيف ب وذلك عندما :

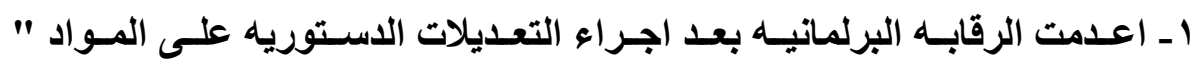

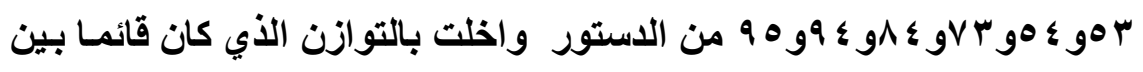
السلطتين التففيذيه والتشريعيه لصالح السلطه التنفيذيه . 
r ـ وعززت عدم الاستقرار الوزاري حيث بلغ عدد الوزارات التي شكلت في الاردن

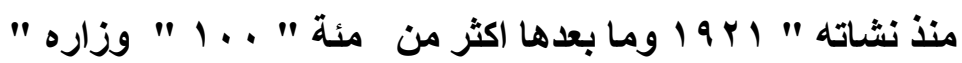

r- وعندما عطلت الحيـاة التيابيه مسن خلال كثرة حل مجلس الواب ومـن خلا

تجميا الحياه النيابيه لفتره طويله وكان من نتائجها فصل الضقة الغربيه عن

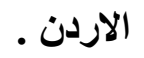

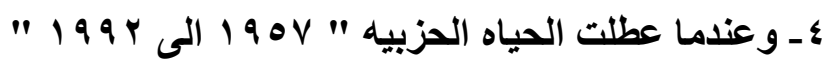




\section{النصل الثاني \\ في حول العوده للمكم الدستوري وبروز العدائيه

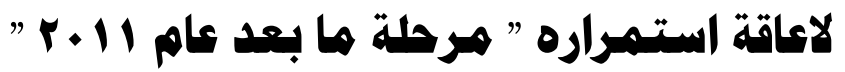

\section{المبحث الاول \\ في العوده للمكم الدستوري}

وقد تم ذلك في يوم خالد بحق للاستور هو " / ـ 11/ ـ ب " حيث تم نشر

التعديلات الاستوريه التي ادخلت على qس مـادة من مواد الاستور في مجالي السلطه

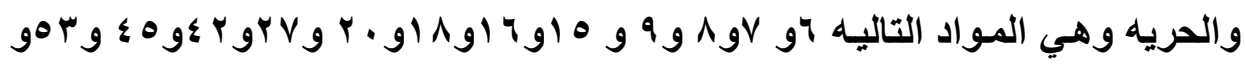
ع هوه هو צ

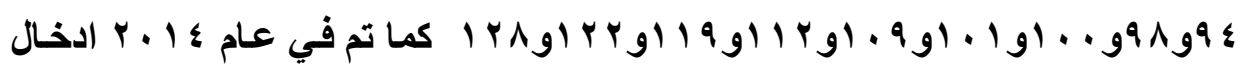

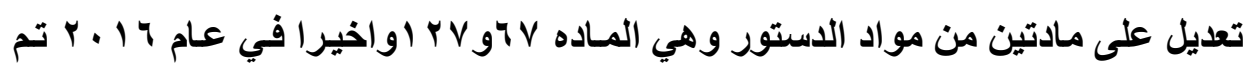

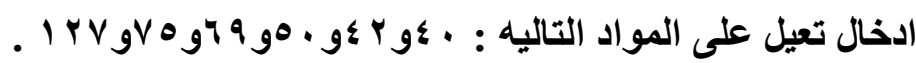
وهنــا لا بـــ مـن وقفـه امــام هـــه التعـديلات التـي جـاءت لتطـوير الـشرعيه

legitimite والمشروعيه السياسيه legalite constitutionelle الميه

(') politique

(1) يراجع حول حق الثعب باعادة النظر في الدستور لتطوير الشرعيه والمشروعيه الدستوريه -

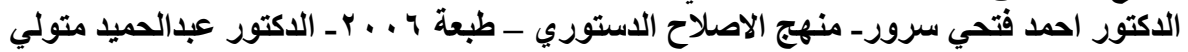

ـ الوسيط في القانون الدستوري ـ طبعة الاسكندريه - 1909 ـ 19 
وهنا لا بد من وقفه امام هذه التعديلات لنجدها قد ارست امرين اثنين هـامين " الذهاب بالنظام السياسي والاستوري للمملكه الى افـق ارحب حيث مكنت من العوده الى الحكم الاستوري وبالتالي الملكيه الدستوريه وامـا الامر الثاني فقد اعاد الحكم الاستوري الى الوراء حيث خلق اضطرابا في جاتب هام من جوانب الحكم الدستوري وبناء عليه سنبدأ من البدايه .

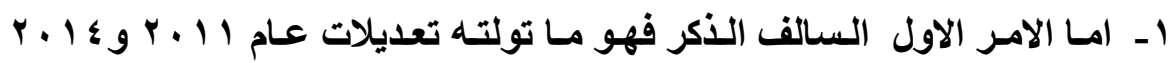
حيث تم بناء عليها ووفقا لها نبذ ذلك الذي قاد الى افساد واضطراب الحياه الاسـتوريه وعالجت في نفس الوقت مـا يعزز النهـوض بكل مـن السلطه والحريه وفق مسارين خالدين :

$$
\text { أ- وهو مسار روجعت فيه :- ت }
$$

ا ـ النـصوص الدسـتوريه الخاصـه بـالحقوق والحريـات العامـه لتتـتج هـذه المراجعه بث الطمانينه لاى الشعب بان الدستور لهم وهم اصحابه وبانـه ليس غريبـا عنهم مـا دام يضمن حقوقهم وحريـاتهم ويؤمن مصالحهم

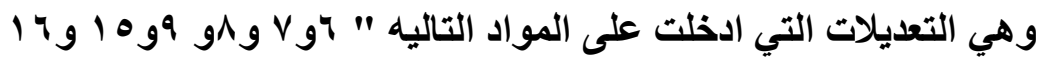

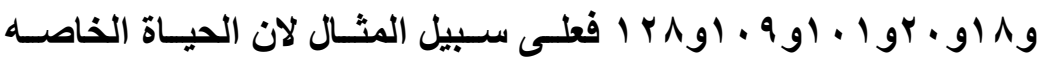
ترتبط بكرامة الانسان وحريته فهي كما يرى الفقه الدستوري قلب الحريه في الاول الحديثه ولقد اثبت التاريخ ان الدول التي تعني وتهتم بكرامـة وخصوصية شعوبها تتقلم وتعلو والدول التي تهار كرامـة وخصوصيات مواطنيها تنهار وتهوي ولهذا يجب على الدول التي ترغب في التقدم

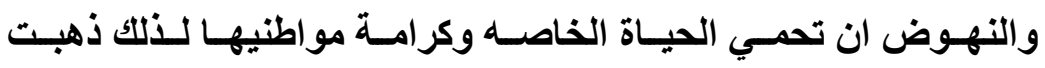
التعديلات الى النص على حق الحياة الخاصه وضرورة حماية هذا الحق 
" V " "، ولان التعذيب يعتبر من اقصى صور انتهاك حقوق الانسان يمكل بالمعارضـه وقد يكون احد صـور العقاب والار هـاب لبعض الافراد وقد يكون للحصول على دليل مـا في مجـال البحث الجنـائي فقد اكدت التعديلات الاستوريه على رفضه وقررت عدم مشروعيته " م 1 " كمـا

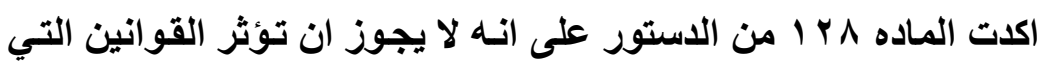
تصدر بموجب هذا الاستور لتظيم الحقوق والحريـات على جوهر هذه الحقوق او تمس اساسياتها (') ץ ـ كمـاروجعت النصوص التـي انتجـت تششويها للشكل النيـابي البرلمـاني ومساسا باسسه وركائزه ليتم في ضوئها نبذ هذا التشويه وهذا المساس ويعيد التوازن والتعـاون بـين السلطتين التتقيذيـه والتشريعيه وهي

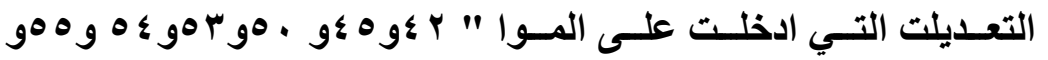

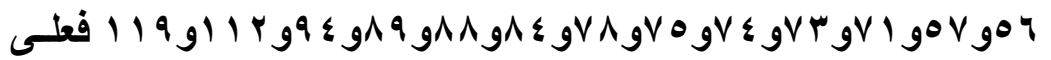
سبيل المثال الزمت الماده به الوزاره ان تتقدم ببيانها الوزاري في كل الحالات وعالجت الامر عندما لم يكن المجلس منعقدا او منحلا كمـا اعيد وفقا لنص الماده هـ تنظيم مسالة محاكمة الوزراء واسقطت التعديلات من الماده VT النص على تاجيل اجراء الاتتخابات وتعطيل الحياه النيابيه

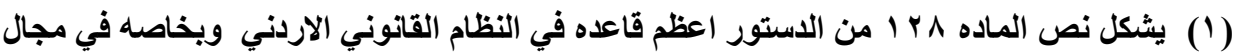

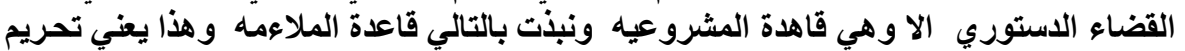

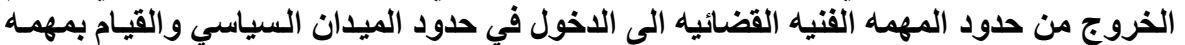

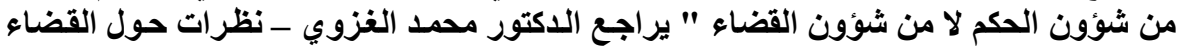

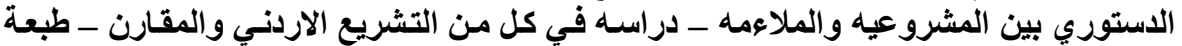

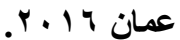


واعـادت المـاده ؛ 9 الخاصـه بـالقوانين المؤقته الـى اصـلها لتهـدم بـلك ماخذا كبيرا على نظامنا القانوني .

ب- وهو المسار الثاني الذي يذهب بالنظام السياسي والدستوري للمملكه الى افاق ارحب وقد تولته بقية التعديلات سـالفة الذكر حيث اكدت في المـاده عV rV القضائيه تستمد وجودها وكيانها من الاستور لا من التشريع .

وهي سلطه اصليه تقف على قدم المساواه مـع السلطه التشريعيه والتنفيذيها وتعبر هذه الاضافه من ناحيه عن اهمية استقلال القضاء وتؤكل من ناحية ثانيه تحرر سلطة القضاء من اي تدخل من جاتب السلطتين التنفيذيه والتشربعيه وعدم خضوع هنوه القضاء لغير القانون وتترجم هذه الاضـافه انسجاما حقيقيا مـا بين النظام القانوني الاردني والجهد الدولي في هذا الخصوص (') واضافت الماده ^9 من الاستور مؤسسه دستوريه هامه " ينشأ بقانون مجلس قضائي يتولى جميع الثؤون المتعلقه بالقضاة النظاميين . كما اضافت التعديلات جديدا اخـر عظيم ومهـم " انـشاء قضاء اداري على درجتين " م. . 1 " وانشاء محكـة دستورية : المواد ^ه وما بعدها من الدستور ، ووفقا لتعديلات ع ا ـ ب التي ادخلت على الماده VT اضيف " انثاء بقانون هيئه مستقله تدير الانتخابات النيابيه والبلديه. واي انتخابات عامه ... " 


\section{المبحث الثاني}

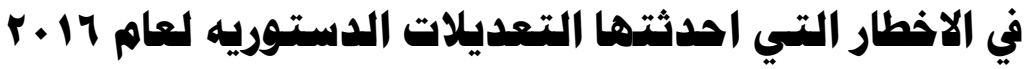

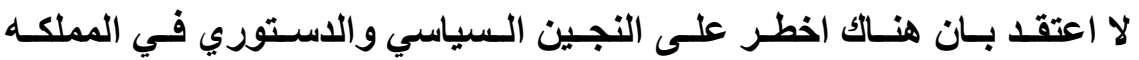

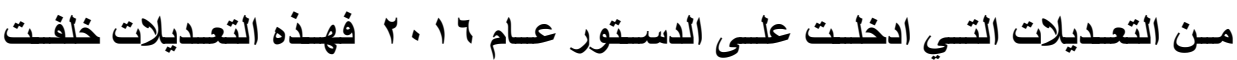

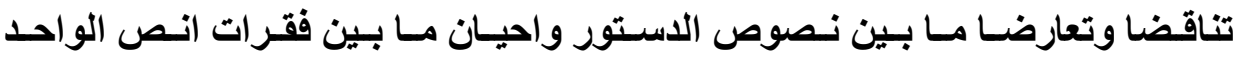
وقـادت في مجموعهـا السى اضـطراب دسـتوري غيـر مسالوف في النظم الدسـتوريه

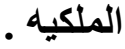

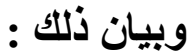

ان تعديل المـاده · ؛ من الاستور جعلها تتكون من فقرتين : الاولى) تتحدث

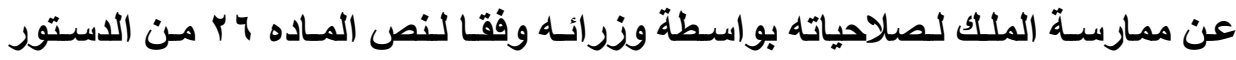
بارادة ملكية موقعه من رئيس الوزراء والوزير او الوزراء المختصين ويبدي الملك موافقته بتثبيت توقيعه فوق التواقيع المـكوره ـ الثانيـه ) وهي تضيف جديدا غير مالوف في مجالي " المصطلحات " والشؤون العامسه " جاء فيها " يمـارس الملك صـلاحياته وفقـا لنص المـاده ؟ ب مـن الاسـتور بـار ادة ملكيـه دون توقيع مـن رئسيس الوزراء والوزير او الوزراء المختصين في الحالات التاليه : اختيار ولي العهد تعيين نائب الملك تعيين رئيس مجلس الاعيان واعضائه وحل المجلس وقبول استقالة او اعفاء اي من اعضائه من العضويه تعيين رئيس المجلس القضائي وقبول استقالته تعيبين رئسيس المحكمسه الدستوريه واعضائها وقبول استقالاتهم تعيبين قائــ الجيش ومدير المخابرات ومدير الارك واتهاء خدماتهم . 
وهنا لا بل من وقفه امام عبارة " يمارس الملك صلاحياته " فهذه تعني اشترالك

الملك في اعمال كل من السلطتين التشريعيه والتنفيذيه والقضائيه ، " تراجع المواد

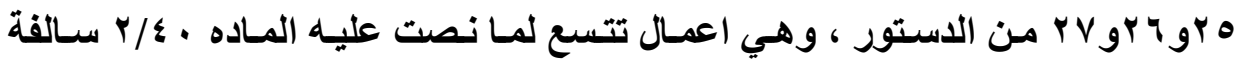

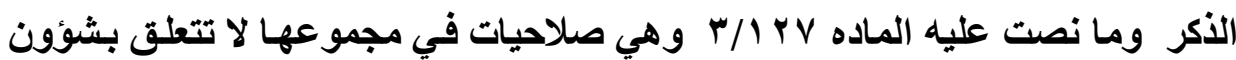
خاصـه ولكنهـا تتعلق بالدولـه وشـؤونها العامـه التـي حرم الاستور ممارستها بشكل منفرد ولكن بواسط الوزراء وهي عباره " اي بواسطة وزرائه " اكثر تقييدا من عبارة " مع وزرائه "

هذا الجديد الذي اضافه التعديل سالف الأكر يتـاقض ويتعارض مـع مـا تـامر بـه نصوص الاستور وبخاصه المواد ^ Y وه V من الاستور ونـضيف بـعـة جديـدة اخـرى فـي التعـديل سـالف الـذكر حيـ تلغـي الخـط

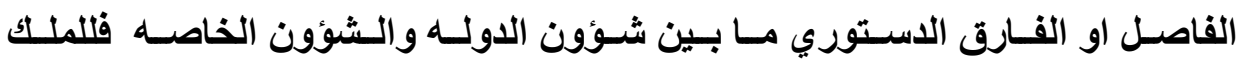
شـؤونه الخاصـه حيـث ذهبـت دسـاتير الـدول الملكيـه الـى اعتمـاد مسطلح " الامسر الملكي recrit royal غير المقيد بمعنى انسه لا يحتـاج الـى توقيع اي وزير مسؤول لممارسة هذه الثؤون الخاصه ونعود لنؤكد ان مـا تضمنته الفقره الثانيه من المـاده

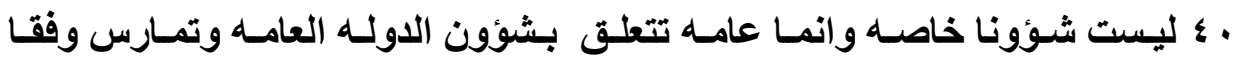
لمصطلح decret او الاراده الملكيه التي تصدر لاستعمال الحقوق التي يتولاهـا الملك (1) بواسطوزرائه .

(1) يقول الفقه الاستوري بان دائرة حقوق الرئيس الاعلى تكاد تكون قاصره في الدول البرلمانيه

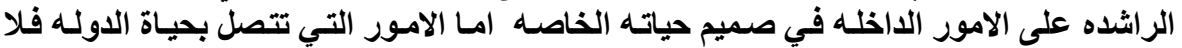

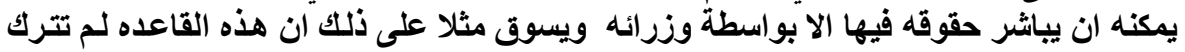
للملك جورج الثامن في انجلتر الحرية في اختيار شريكة حياته وملكة بريطانيا مستقبلا. 


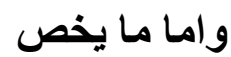

" حمل دوله اجنبيه " التي اجازنها المواد ، ؛ من الاستور للوزير والمساده

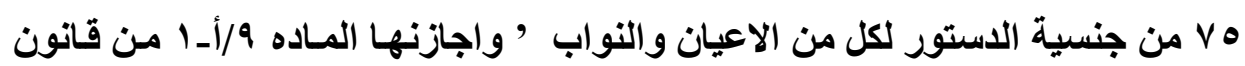

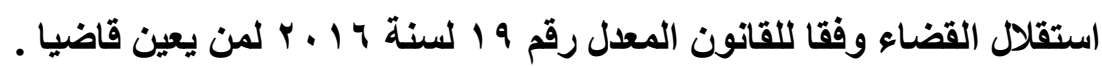
فاتنا نجد في هذا انتاجا سيئا اخر للمسار فمن ناحيه هناك تعارض وعدم اتسجام مـع المواد 9 بو بـو • 1 من الدستور الخاصه بالقسم لكل من الملك ورئيس الوزراء والوزراء واعضاء مجلسي الاعيسان والنواب ولا تنسجم مع ما امرت به الماده ؛ ا من قانون استقلال القضاء التي الزمت بـاداء القسم " امسام الملكت وامسام رئسيس المجلس القضائي وامسام رئسيس المجلس القضائي " فهوؤلاء يشظلون مناصب سياديه يكون لشاغلها كمـا يقول فقه القـانون العام (') القدره على القيام بعمل من اعمـال السياده او المشاركه فيه بصوره مباشره وفقا لما يامر به الدستور والقوانين ـ ولهذا لا يجوز اسناد هذه المناصب . ا - يقول الفقـه الاسـتوري بـان دائرة حقوق الرئيس الاعلى تكـاد تكـون قاصره

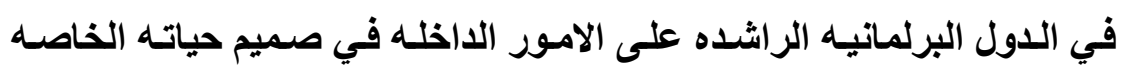

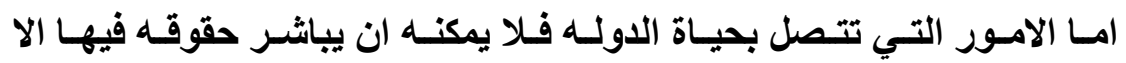

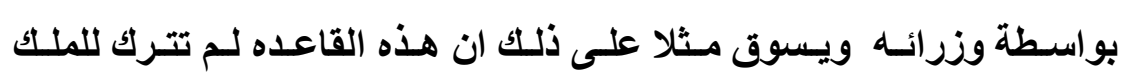
جورج الثـامن في انجلتراالحريـة في اختيـار شـريكة حياتـه وملكـة بريطانيـا مستقبِلا .

(1) الاكتور محمد فؤاد مهنا - سياسة الوظائف العامه وتطبيقاتها في ؤضوء مباديء علم التنظيم القاهره VT 94. 
الخطيره لمن يحمل جنسية دوله اخرى والى هذا ذهب كل من الفقهـ الاستوري والقضاء الاداري حيث يقول كل منهمـا ان القسم الاستوري يفترض وحدة الجنسيه وان متعدد الجنسيه يكون متعدد الولاء ... ونضيف ان من ينتمي لدولتين بحكم تمتعه بنسيتين ينشطر ولاؤه قانونا الى ولائين . ومن ناحيه ثانيه انتج تعارضا وتناقضا بين فقرات المساده الج من الدستور اتي تنص على شروط عضو المحكمه الاستوريه الاردنيه . ونضيه مظهرا اخر جديد من مظاهر الاضطلراب الاستوري اخذ يشق مسارا ضارا وخطيرا الاوهو عدم الاستقرار الوزاري بنكهه مختلفه تتلخص في الالتفـق على ما تامر به المواد اه ومـا بعدها من الدستور وبالتشالي مخالفتها واهدار الالتزام 


\section{الخاتهه}

اما وقد انتهينـا من الحديث عن التشريع الدستوري في المملكه ( (1) (1) ومـا

انتابه وواجهه من اضطراب تجاوزه في المرة الاولى ولم يتم تجاوزه في المرة الثانيه وما زال يعاني منه ـ وهنا لا بـ من وقفه لنذكر ان مسارا يطال الدستور ويحوله الـى لعبـه للتفكيك هو الاكثر خطوره على النهجين السياسي والاستوري ـ ونـضيف ان الصمت حول ما يطال الاستور لا يقل خطوره الامر الذي يـعونـا الى اختراقه ونضع

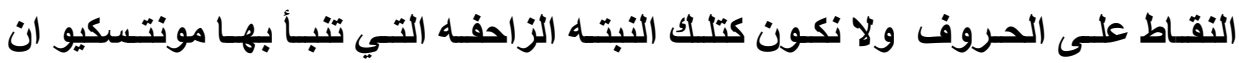
الاضطر اب الاستوري الذي عـانى منـه الاردن ومـا زال يعـاني ليس قدرا وانمـا جـاء بفرديـه وعدائيـه خفيـه للمؤسسـات السياسيه والاسـتوريه الاردنيـهـ وممسن يعتبرون انفسهم الدوله الذين قال عنهم ووصفهم مونتسكيو بالنبته الزاحفه التي تلتصق بكل ما تجده في طريقها حيث كـان الاولس بهؤلاء عندما يتعلق الامـر بالملكـ ان يراعوا

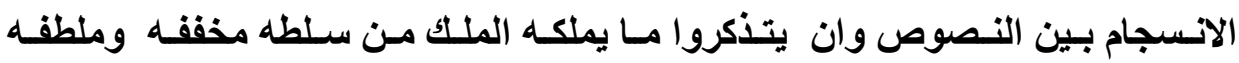
pouvoir moderateur " التي وصفت بمفاتيح الدوله السياسيه (ץ) والتي يكفلها الاستور " تعيين رئيس الوزراء والوزراء واقالتهم ، استعمال سلطته بحل مجلس النواب ، تلخله في العمليه التشريعيه وبخاصسه التصديق وفقا لنص المساده ب9 من الاستور الرفض الأي يملكه على الاعمال التي يقترح عليه توقيعها "

(1) (ما القوانين المكمله وبخاصه تلك التي تنظم المفاصل الاساسيه للاوله الاردنيه سنتاولها بالبحث

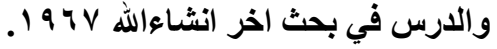

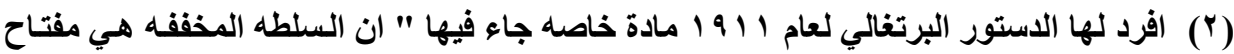

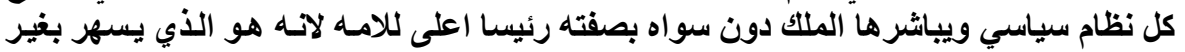
انقطاع على بقائها و استقلالها و على توازن السلطات السيات رئياء. 


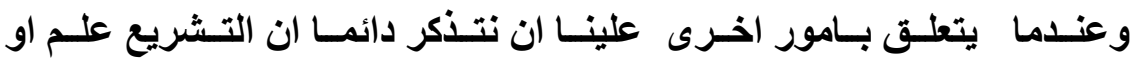

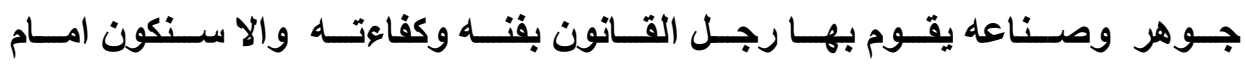
سياسـه تشريعيه سيئه و وا مسام نوعيهه من التشريع رديئه ثرثناره متناقضه و ضـاره فاين نحن من السياسه التشريعيه المتقنه العادله واين نحن من نوعية التشريع غير الضار ؟

ولان الامر مـاز زال يشكل ضـررا بالغـا فانتـا نــعو الى الاسـراع بالذهاب الى الاصللاح ذ ذلك لان مواطنه عديده متعدده بعضها قد تتفق والحلول الفوريـه كتقديم الاقوى على الاضعف في مواجهة التناقض والتعارض ببين نصوص الاستور وفي هذا

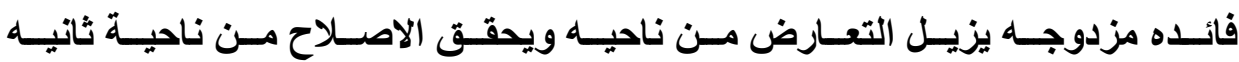

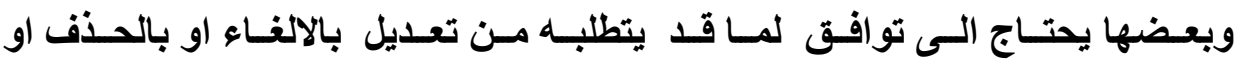
بالاضافه . 